\title{
Evolution of a photonics education program
}

\section{Alexander McGlashan, Jay Yatulis}

Alexander McGlashan, Jay Yatulis, "Evolution of a photonics education program," Proc. SPIE 9665, Tenth International Topical Meeting on Education and Training in Optics and Photonics, 96650S (3 June 2007); doi:

$10.1117 / 12.2207322$

SDIE Event: Tenth International Topical Meeting on Education and Training in Optics and Photonics, 2007, Ottawa, Ontario, Canada 


\title{
Evolution of a Photonics Education Program
}

\author{
Alexander McGlashan ${ }^{*}$, Jay Yatulis \\ Niagara College, 300 Woodlawn Road, Welland, ON, Canada L3C 7L3
}

\begin{abstract}
The Photonics Technology program at Niagara College was first launched in 2001. Since that time, in an attempt to meet the joint needs of industry and students, Niagara has developed the technology program into a cluster of four programs related to photonic technology. Niagara is also building relationships with universities to deliver photonic course material to physics undergrad students using Niagara College Photonics facilities and faculty to create an undergraduate specialization in lasers.

This paper will review the development of the photonics cluster at Niagara College and present the current state of its evolution.
\end{abstract}

\section{INTRODUCTION}

As a result of the proliferation of photonic technology in virtually every sector of industry, many companies find themselves without the necessary optical and electro-optical expertise. In 2001 the Ontario Photonics Education and Training project (PET) established completely new Photonics Engineering Technician (2 years) and Photonics Engineering Technologist (3 years) programs at Niagara and Algonquin Colleges. With the conclusion of the 2007 winter term, Niagara College will have educated 3 cohorts of Photonic Engineering Technologists, and 4 cohorts of Photonics Engineering Technicians. Since the initial launch of these two programs both colleges have expanded their offerings in photonic education. This growing demand for photonic professionals is what fueled the creation of the original two Photonic programs. With the initial graduating class has come acceptance of Photonic Technicians and Technologists by industry. With acceptance has come greater demand for more professionals trained in the discipline of photonics. To this end Algonquin and Niagara Colleges have introduced a 4-year Bachelor of Applied Technology or BAT in Photonics, and Niagara College a 1-year Advanced Lasers Graduate Certificate. Although graduates are being readily hired by industry, recruitment of students into these new and often misunderstood programs has proven to be a substantial challenge.

\section{PHOTONICS PROGRAMS}

\subsection{Introduction}

In this section the individual photonic programs at Niagara will be reviewed. Changes in the program curriculum since inception will be described, and the reasons for those changes discussed.

\subsection{Photonics Engineering Technology}

The Photonics Engineering Technology program as launched in 2001 ran for 3 consecutive intakes from Fall 2001 until Fall 2003. In Fall 2004, Niagara College suspended intake of the Technology program in an attempt to bolster numbers for the new 4-year Bachelor of Applied Technology (Photonics) program. The removal of the 3-year program created a gap in the college's ability to retain students within the Photonics cluster. Students who had difficulty coping with the rigor of the BAT (Photonics) had only the option to transfer to the 2-year technician program if they were to remain in Photonics despite being better suited to a 3 -year technology program. The lack of a 3-year program could be a contributing factor in poor retention rates in keeping BAT students within the Photonics cluster.

In 2006 changes were proposed and accepted to modify the curriculum of the Photonics Technology program. The Photonics Technology program is currently accepting an intake for the Fall 2007 term under the new model and is expected to run.

Tenth International Topical Meeting on Education and Training in Optics and Photonics, edited by Marc Nantel, Proc. of SPIE Vol. 9665, 96650S - @ 2007 SPIE, OSA, IEEE, ICO doi: $10.1117 / 12.2207322$ 
The adopted program model provides laddering of the Technician curriculum directly into that of the Technology program. Under the new model both the Technology and Technician programs share a common first year. Second year is also common with the exception of math courses. The new program model is shown in Table 1. This model provides students with several opportunities for movement within the photonics cluster. For struggling technologists it provides an exit point after two years which will provide the student with a Technician diploma. It also provides easy lateral movement for Technicians who after one or two years in the system decide to complete the third year and graduate with a Technologist diploma. When combined with courses designed to provide bridging from Technology to BAT, this model provides a complete pathway from Technician to BAT and in an attempt to maximize retention it provides a reverse pathway from BAT to Technician.

Some of the changes in curriculum address the recommendation made in the paper Technician and technologist photonics teaching: An Ontario success story Jay Yatulis et. all. In order to improve the students electronics manufacturing skill set a new course has been introduced. Manufacturing Technology for Photonics is a 3-hour per week course delivered in term 2. As an introductory course in manufacturing technology it exposes students to through-hole and surface mount soldering, epoxies, and printed circuit board fabrication. This will allow more advanced manufacturing technologies to be explored in the preexisting Manufacturing Photonics Components, and Photonics Manufacturing Systems courses.

When combining the Technology and Technician streams it was necessary to replace the Technologist version of Light and Lasers Principles with the Technician version. In order to improve the rigor of the Technologist's light and laser theory, the addition of the Advanced Laser Theory ( 3 credits) course in term 5 was made.

Another improvement made to the curriculum was to modify the Photonics Research Project so that it spans terms 5 and 6 (originally term 6 only). This will allow an improved treatment of the project, enable students to generate more reasonable timelines, and hopefully provide longer more meaningful contacts with industry partners. The first term will be used to develop the project and finalize details on what is to be accomplished. Any materials for fabricated parts of a design would be ordered at this time. The second term will be used to perform and complete any testing. A comprehensive paper will be prepared for the conclusion of this course

\subsection{Photonics Engineering Technician}

The Photonics Engineering Technician program has gone through several iterations since its initial launch in Fall 2001. Students of the first cohort were enrolled into the same core courses as Technologist students. In many cases the difficulty of the technologist courses was above the ability of students enrolled at the Technician level. This resulted in the creation of modified courses to provide an improved academic fit within the Technician program. The introductory manufacturing course described in 2.2 was introduced into the program for the Fall 2006 cohort. As discussed in 2.2 the current version of the Technician program is once again common with the Technologist program. In the new model Technician level courses are delivered to both streams, and additional theory is introduced in year 3 of the Technologist program to maintain the academic rigor of that program. 
Photonic Engineering Technician

\begin{tabular}{|c|c|c|}
\hline Crs. No. & Course Name & Hrs. \\
\hline \multicolumn{3}{|l|}{ LEVEL 1} \\
\hline CTEC1544 & Computer Programming \& Applications & 60 \\
\hline ENGL1133 & College English & 45 \\
\hline MATH1131 & Mathematics I for Technology & 60 \\
\hline PHYS1108 & Optics \& Waves & 105 \\
\hline TECH1244 & Health \& Safety for Technology & 45 \\
\hline TECH1271 & Future Trends in Advanced Technology & 45 \\
\hline \multicolumn{3}{|l|}{ LEVEL 2} \\
\hline ELNC1220 & Electrical Principles for Photonics & 75 \\
\hline MATH1231 & Mathematics II for Technology & 60 \\
\hline MMFG1279 & Manufacturing Technology for Photonics & 45 \\
\hline PHTN1220 & Optic/Optical Fibre Principles & 90 \\
\hline PHYS1220 & Kinematics \& Dynamics & 75 \\
\hline \multicolumn{3}{|l|}{ LEVEL 3} \\
\hline CTEC1330 & Data \& Telecommunications & 60 \\
\hline ELNC1320 & Electronic Principles for Photonics & 90 \\
\hline MATH1299 & Statistics for Technicians & 30 \\
\hline PHTN1300 & Principles of Light Sources and Lasers & 75 \\
\hline PHTN1334 & Fibre Optics Communication & 75 \\
\hline GenEd & General Education Elective & 45 \\
\hline \multicolumn{3}{|l|}{ LEVEL 4} \\
\hline ELNC1430 & Digital Technology & 60 \\
\hline PHTN1400 & Principles of Laser Systems & 75 \\
\hline PHTN1431 & Manufacturing Photonics Components & 75 \\
\hline PHTN1432 & Vacuum \& Thin Film Coating Applications & 60 \\
\hline GenEd & General Education Elective & 45 \\
\hline
\end{tabular}

Photonic Engineering Technology

\begin{tabular}{|c|c|c|}
\hline Crs. No. & Course Name & Hrs. \\
\hline \multicolumn{3}{|l|}{ LEVEL 1} \\
\hline CTEC1544 & Computer Programming \& Applications & 60 \\
\hline ENGL1133 & College English & 45 \\
\hline MATH1131 & Mathematics I for Technology & 60 \\
\hline PHYS1108 & Optics \& Waves & 105 \\
\hline TECH1244 & Health \& Safety for Technology & 45 \\
\hline TECH1271 & Future Trends in Advanced Technology & 45 \\
\hline \multicolumn{3}{|l|}{ LEVEL 2} \\
\hline ELNC1220 & Electrical Principles for Photonics & 75 \\
\hline MATH1231 & Mathematics II for Technology & 60 \\
\hline MMFG1279 & $\begin{array}{l}\text { Manufacturing Technology for } \\
\text { Photonics }\end{array}$ & 45 \\
\hline PHTN1220 & Optic/Optical Fibre Principles & 90 \\
\hline PHYS1220 & Kinematics \& Dynamics & 75 \\
\hline \multicolumn{3}{|l|}{ LEVEL 3} \\
\hline CTEC1330 & Data \& Telecommunications & 60 \\
\hline ELNC1320 & Electronic Principles for Photonics & 90 \\
\hline MATH1331 & Mathematics III for Technology & 45 \\
\hline PHTN1300 & Principles of Light Sources and Lasers & 75 \\
\hline PHTN1334 & Fibre Optics Communication & 75 \\
\hline GenEd & General Education Elective & 45 \\
\hline \multicolumn{3}{|l|}{ LEVEL 4} \\
\hline ELNC1430 & Digital Technology & 60 \\
\hline PHTN1400 & Principles of Laser Systems & 75 \\
\hline PHTN1431 & Manufacturing Photonics Components & 75 \\
\hline PHTN1432 & Vacuum \& Thin Film Coating Applications & 60 \\
\hline GenEd & General Education Elective & 45 \\
\hline MATH1431 & Mathematics IV for Technology & 45 \\
\hline \multicolumn{3}{|l|}{ LEVEL 5} \\
\hline ENGL1430 & Technical Communications & 45 \\
\hline MATH1637 & Statistics & 45 \\
\hline PHTN1500 & Advanced Laser Theory & 45 \\
\hline PHTN1530 & Advanced Optical Systems & 75 \\
\hline PHTN1531 & Opto-Electronic Devices & 60 \\
\hline PHTN1533 & Photonics Research Project I & 30 \\
\hline PHYS1630 & Heat Transfer & 60 \\
\hline \multicolumn{3}{|l|}{ LEVEL 6} \\
\hline ELEC1532 & Industrial Controls - PLC & 75 \\
\hline PHTN1630 & Photonics Manufacturing Systems & 75 \\
\hline PHTN1631 & Imaging/Image Processing & 60 \\
\hline PHTN1632 & Laser/Matter Interaction & 75 \\
\hline PHTN1633 & Photonics Research Project II & 45 \\
\hline
\end{tabular}

Table 1 Photonics Technician and Technology Programs of Instruction 


\subsection{Bachelor of Applied Technology (Photonics)}

The Bachelor of Applied Technology (Photonics) or BAT was launched in Fall 2004. The 4-year BAT program is designed to provide industry with photonic undergraduates who possess the theoretical background comparable to that of a university undergraduate science degree and also to provide an individual with hands-on technical skills comparable to that of a Technologist. The graduate of this program is industry ready, requiring minimal on-the-job training.

The curriculum of the BAT program is unique in that it is modeled after a top down approach to learning. As shown in Table 2, students of the BAT program are exposed to applications of photonics immediately in term one. Unlike a traditional university degree which begins with minimal exposure to the discipline of choice, instead focusing solely on the fundamentals, the BAT degree immerses the students in lab based activities exposing them to advanced applications and concepts immediately. Initially these concepts are treated from a perspective not requiring an understanding of the underlying principles. As the program progresses more of these principles behind the concepts are revealed until the student is left with a complete understanding of both fundamentals and advanced concept. The advantage of this model is that it engages the student into the material from day one. Attrition is often the result of students losing interest in the material, or failing to understand how the fundamentals being studied relate to the applications that may have drawn the student into the program in the first place.

The BAT program received a second intake of students in Fall 2005, but the intakes for Fall 2006 and 2007 have been suspended due to recruitment difficulties. Although the college's industry partners have expressed interest in the graduates of this program, the challenges of recruiting university level students to take a degree at a college has proven problematic. Science and technology teachers at the secondary school level have proven to be invaluable allies in correcting the misconception that a college BAT degree is somehow less valuable than a university Bachelor's degree. 


\begin{tabular}{|c|c|c|}
\hline \multicolumn{2}{|l|}{ LEVEL 1} & \multirow[b]{2}{*}{ Hrs. } \\
\hline Crs. No. & Course Name & \\
\hline BATP9101 & $\begin{array}{l}\text { Occupational Health and Safety and } \\
\text { Ethics }\end{array}$ & 45 \\
\hline ВАТР9102 & Optics and Waves & 75 \\
\hline ВАТР9103 & Trends in Photonics & 45 \\
\hline BMAT9104 & Calculus I & 60 \\
\hline BPRO9105 & Programming I & 45 \\
\hline BSCI9106 & General Chemistry & 45 \\
\hline \multicolumn{3}{|l|}{ LEVEL 2} \\
\hline BATP9201 & Optics/Optical Fibre Principles & 75 \\
\hline BELN9202 & Electro-technology & 75 \\
\hline BMAT9203 & Calculus II & 60 \\
\hline BPRO9204 & Programming II & 45 \\
\hline BSCI9205 & Kinematics and Dynamics & 60 \\
\hline \multicolumn{3}{|c|}{ LEVEL 3} \\
\hline BATP9301 & Fundamentals of Light Sources & 75 \\
\hline ВАТР9302 & Interfacing & 60 \\
\hline ВАТР9303 & Optics/Optical Fibre Devices & 60 \\
\hline BELN9304 & Semiconductors and Logic & 60 \\
\hline BMAT9305 & Linear Algebra & 45 \\
\hline \multirow[t]{2}{*}{ CPLN9061 } & Career Planning and Development & \\
\hline & Liberal Studies Elective & 45 \\
\hline \multicolumn{3}{|c|}{ LEVEL 4} \\
\hline ВАТР9401 & Laser Systems & 75 \\
\hline ВАТР9402 & $\begin{array}{l}\text { Manufacturing Photonics } \\
\text { Components }\end{array}$ & 60 \\
\hline ВАТР9404 & Telecommunications & 60 \\
\hline BCOM9403 & Technical Communications & 45 \\
\hline BMAT9405 & Differential Equations & 45 \\
\hline BMAT9406 & Statistics & 45 \\
\hline \multicolumn{3}{|c|}{ LEVEL 5 Co-op } \\
\hline COOP9402 & Co-op Work Placement I & \\
\hline
\end{tabular}

\begin{tabular}{|c|c|c|}
\hline \multicolumn{3}{|l|}{ LEVEL 6} \\
\hline $\begin{array}{l}\text { Course } \\
\text { Name }\end{array}$ & Course Name & Hrs. \\
\hline BATP9501 & Advanced Optical Systems & 75 \\
\hline BATP9502 & Control Systems & 60 \\
\hline BATP9503 & Photonics Manufacturing Systems & 75 \\
\hline \multirow[t]{2}{*}{ BATP9504 } & Thin Film and Vacuum Systems & 75 \\
\hline & Liberal Studies Elective & 45 \\
\hline LEVEL 7 & Co-op & \\
\hline COOP & Co-op Work Placement II & \\
\hline \multicolumn{3}{|l|}{ LEVEL 8} \\
\hline BATP9601 & Image/Signal Processing & 60 \\
\hline BATP9602 & Opto-Electronic Devices & 75 \\
\hline BMAT9603 & Advanced Calculus & 45 \\
\hline BMGT9604 & Business Principles & 60 \\
\hline \multirow[t]{2}{*}{ BSCI9605 } & Electro-Magnetic Theory & 45 \\
\hline & Liberal Studies Elective & 45 \\
\hline LEVEL 9 & Co-op & \\
\hline $\mathrm{COOP}$ & Co-op Work Placement III & \\
\hline \multicolumn{3}{|l|}{ LEVEL 10} \\
\hline BATP9701 & Advanced Optical Theory & 45 \\
\hline BATP9702 & Photonics Research Project & 60 \\
\hline ВАТР9703 & Thermodynamics and Heat Transfer & 45 \\
\hline BSCI9704 & Materials Science & 60 \\
\hline \multirow[t]{2}{*}{ BSCI9705 } & Quantum Physics & 45 \\
\hline & Liberal Studies Elective & 45 \\
\hline \multicolumn{3}{|l|}{ LEVEL 11} \\
\hline BATP9801 & Advanced Research Project & 60 \\
\hline BATP9802 & Bio/Medical Photonics & 60 \\
\hline BOPS9803 & Operations Management & 60 \\
\hline BSCI9804 & Solid State Physics & 45 \\
\hline & Liberal Studies Elective & 45 \\
\hline
\end{tabular}

Table 2 Bachelor of Applied Technology (Photonics) Program of Instruction 


\subsection{Advanced Lasers Graduate Certificate}

The Advanced Lasers Graduate Certificate is a one year program providing an amalgam of courses running in the BAT and Technology programs. The program received approval from Niagara College to run its first intake for Fall 2007. This intake was later suspended as a result of low application numbers (public marketing for the program did not receive approval until February 2007). The college will be marketing for a Fall 2008 intake.

The Advanced Lasers program was designed to accomplish two tasks;

1. Provide skilled and theoretical laser training to those with a technical or engineering background

2. To economize the BAT (Photonics) program.

The program provides students with the expertise to work at an advanced operator or design level and is open to any student with a science or technology diploma and/or degree, including electronics, mechanical and electrical engineering technology graduates. The applied \& practical skills acquired in this program are required for direct entry into industry which should be of particular interest to students of university physics programs which are classical in nature. The program provides hands-on experience in the areas of laser operation, maintenance, reprocessing and design. With the exception of business principles, every course in this program features a major laboratory component.

The Advanced Lasers program was originally designed to leverage off of preexisting courses from the BAT and Technology programs, using students of the Advanced Lasers program to help offset the effect of attrition of students. This was seen to provide improved economy of the BAT program and year 3 of the Technologists program, while at the same time providing a useful service to industry, and engineering professionals. Since the design phase of the program much has changed. The program has necessarily morphed into one that can be delivered independent of the other photonics programs. In order to recruit the additional students required to allow the Advanced Lasers program to run independently Niagara has created a partnership with Brock University.

An articulation agreement between the Brock University Bachelor of Science Honours Degree in Physics and the Niagara College Advanced Lasers Graduate Certificate program has been created. The Senate of Brock University has approved the establishment of a concentration in Applied Optics and Laser Technology within its current honours Bachelor of Science program. This agreement is designed to enable students to complete concurrently an honours degree in Physics from Brock University and a graduate certificate in Advanced Lasers from Niagara College. The current structure of the Advanced Lasers Graduate Certificate as accepted by both Niagara College and Brock is provided in Table 3. 


\begin{tabular}{|c|l|c|}
\hline LEVEL 1 & Hrs. \\
\hline Crs. No. & \multicolumn{1}{|c|}{ Course Name } & 75 \\
\hline BATP9301 & Fundamentals of Light Sources & 60 \\
\hline BATP9303 & Optics/Optical Fibre Devices & 75 \\
\hline PHTN1530 & Advanced Optical Systems & 60 \\
\hline PHTN1531 & Opto-Electronic Devices & \multicolumn{1}{|c|}{} \\
\hline
\end{tabular}

\begin{tabular}{|c|l|c|}
\hline \multicolumn{1}{|l|}{ LEVEL 2} \\
\hline Crs. No. & \multicolumn{1}{|c|}{ Course Name } & Cr. \\
\hline BATP9401 & Laser Systems & 75 \\
\hline BMGT9604 & Business Principles & 60 \\
\hline MMFG9101 & Laser Maintenance and Manufacturing Technology & 60 \\
\hline PHTN1432 & Vacuum and Thin Film Coating Applications & 60 \\
\hline PHTN1632 & Laser Matter Interaction & 75 \\
\hline
\end{tabular}

Table 3 Advanced Lasers Graduate Certificate Program of Instruction

\subsection{Additional Academic Options}

Niagara College currently offers additional academic options to students of the Photonics programs. Given the similarities in program curriculum between photonics and other technology programs, select Photonics graduates have been provided with a one year advanced standing in Niagara College's Electronics, and Electrical Technician programs. The completed dual diploma has proven to be extremely popular with employers looking for employees with a broad base of experience.

In partnership with the Hoseo University of Korea, Niagara College is piloting a hybrid English as a Second Language (ESL) and Photonics Technology program. This project will bring select students who have completed their second year in the Bachelor of Science at Hoseo University to Niagara College for eight weeks of training. The first six weeks provides traditional ESL training to be followed by two weeks of hands-on training to develop skills in the field of display technology. Niagara College expects to host the first 20 students of this program in July of 2007.

\section{RECRUITMENT}

The challenges and successes of recruiting for the photonics programs at Niagara College have been explored ${ }^{1}$.

In a move to improve recruitment of students the Technology Division has hired an individual with a science background to work part time as a Program Liaison Officer. This individual is responsible for recruiting activities within the division, with special focus on the photonics program cluster. Internally the Program Liaison Officer organizes events, tours, and provides support to Niagara College's recruitment department. The most effective recruitment technique at Niagara College's disposal continues ${ }^{1}$ to be on site tours of the lab facilities by high school students. New recruitment activities have included attendance at popular cultures events such as science fiction exhibitions. The success of recruiting at these events has been mixed, but has resulted in exposure of the program not just at the event, but also by television, print, and Internet media present at the event. 


\section{FACILITIES}

The photonic facilities at Niagara College have previously been described in great detail ${ }^{1}$. Since that time numerous upgrades and improvements have been realized, the most notable as described below;

a. New laser machining lab:
i. Laser Marker
ii. Laser Welder
iii. Laser (Micro)Machining Centre

b. New Class 4 laser lab

c. Dedicated research lab space

i. $100 \mathrm{~W} \mathrm{CO}_{2}$ laser

ii. Pyrocam (10.6um laser profilometer)

iii. Infrared camera system

d. Scanning Electron Microscope

e. Lesker 3 target sputtering thin-film deposition system

f. Two new aerospace grade laser projectors

Additional equipment to be donated to Niagara College, but as yet unrealized includes a computer controlled polisher capable of polishing high-end aspheric lens.

Improvements to facilities and equipment are primarily the result of excellent relations with industry. Employed graduates frequently donate equipment and materials to the college. This shows the good will of our partners, but also demonstrates industries realization that the college is training the next generation of photonic professionals. By training students with equipment donated by industry the college is providing industry with employees who require significantly less on the job training, saving time and money.

\section{RESEARCH}

The introduction of photonics curriculum at the college level occurred at approximately the same time that the province of Ontario began to encourage applied research at College institutions. Given Niagara College's unique collection of photonic facilities and faculty it has become involved in several applied research projects.

Current projects funded by the Ontario InnovationTrust;

a. Laser Applications in the Greenhouse Industry

b. Use of Photonic Technologies to Control Disease Spread in Greenhouse Production

Niagara College is in the process of submitting other proposals that would include research into the areas of display technology and laser induced breakdown spectroscopy.

The applied research projects are designed to help local industry and garner attention for the college and the program. Funded research has resulted in dedicated lab space and new equipment that can be used for both the intended research and as learning tools during scheduled classes. The most important aim of the projects is to involve students in collaborative relationships with industry. Past projects have resulted in employment opportunities for students who have worked with industry on these projects. The research crosses disciplines, and helps to demonstrate to students the importance of breadth of knowledge. 


\section{RECOMMENDATIONS}

\subsection{Co-Operative Learning}

Providing Co-operative learning opportunities for BAT students was initially challenging. This was deemed to be primarily a result of industry's inexperience with a photonics undergraduate degree program, and as a secondary concern most members of industry are seeking eight month placements, where as the BAT program only offers 4 month placement opportunities. As of the end of March 2007, BAT co-op placements are progressing slowly although at an improved rate over the same time in 2006.

Co-ops have been an immensely successful and important component of other Technology programs at Niagara College. They provide on the job training, and industrial experience of the kind that is not reproducible in a class environment. It also provides employers the opportunity to try out students at little risk or cost to themselves and many times results in permanent full-time employment of the student upon graduation.

Co-operative learning is currently missing from the curriculum of the Photonics Technology program. Given the success of co-operative learning in other programs and consultation with members of industry, it is recommended that the Photonics Technology program be aligned with the other existing Technologist programs to include one four month co-op, and one eight month co-op.

\subsection{Facilities}

Optical lens and mirror manufacturers in Ontario have begun to employ graduates of the Photonics programs. Unfortunately the college facilities do not currently include any optical lens manufacturing or polishing equipment on which to train students. One industrial partner has made motions to provide Niagara College with a donation of a lens polisher, and proposed the loan of two others. This will still leave the college with a requirement for equipment for the generation and grinding of lenses and mirrors.

\subsection{Articulations}

Unofficial articulation agreements between Photonics, Electronics, and Electrical programs need to be formalized and expanded. This agreement will allow a student who has completed Photonics at the Technician or Technologist level direct entrance into year 2 of the Electronics or Electrical program. This agreement already exists in principle, and has been used by several students successfully. Formalizing the agreements will allow them to be used as recruitment tools, and hopefully make the Photonics program more appealing to those with interests outside of the Photonics discipline. Other possible articulations into Computer Technology and from Mechanical Technology are being considered.

\section{SUMMARY}

Photonics curriculum at the college level is still a relatively new introduction and is in a continual state of self-improvement. With the assistance of industry partners, graduates, and the students currently in the system, Niagara College is endeavouring to create curriculum that will meet the needs of all parties. Given the continued demand for photonic professionals that has been communicated to the college by industry it is assured that the college photonic programs will enjoy long life in one form or another. As the general populace better understands the term "photonics", and photonic professionals become more ingrained within the fabric of local industry, recruiting pressures will begin to ease. With continual interest by partners to collaborate on applied photonics research, Niagara College is assured exposure not only locally, but internationally. Continual research and donations by members of industry also ensure that students will be training in modern facilities for many years to come. 


\section{ACKNOWLEDGEMENTS}

The author(s) wish to acknowledge the continued support of our industry collaborators, college staff, our partners at Brock and Hoseo universities and the graduates and students of the Niagara College Photonic programs.

\section{REFERENCES}

1. Technician and technologist photonics teaching: An Ontario success story Jay Yatulis et. all

*amcglashan@niagarac.on.ca ; phone (905)735-2211 ext. 7513; fax (905)988-4304; www.niagarac.on.ca 